Review

\title{
Novel Insights into the Development and Function of Cilia Using the Advantages of the Paramecium Cell and Its Many Cilia
}

\author{
Junji Yano, Megan S. Valentine and Judith L. Van Houten * \\ Department of Biology, University of Vermont, Burlington, VT 05405, USA \\ * Author to whom correspondence should be addressed; E-Mail: Judith.Vanhouten@uvm.edu; \\ Tel.: +1-802-656-0452; Fax: +1-802-656-2914.
}

Academic Editors: Gang Dong and William Tsang

Received: 29 May 2015 / Accepted: 24 July 2015 / Published: 29 July 2015

\begin{abstract}
Paramecium species, especially $P$. tetraurelia and caudatum, are model organisms for modern research into the form and function of cilia. In this review, we focus on the ciliary ion channels and other transmembrane proteins that control the beat frequency and wave form of the cilium by controlling the signaling within the cilium. We put these discussions in the context of the advantages that Paramecium brings to the understanding of ciliary motility: mutants for genetic dissections of swimming behavior, electrophysiology, structural analysis, abundant cilia for biochemistry and modern proteomics, genomics and molecular biology. We review the connection between behavior and physiology, which allows the cells to broadcast the function of their ciliary channels in real time. We build a case for the important insights and advantages that this model organism continues to bring to the study of cilia.
\end{abstract}

Keywords: Paramecium; cilia; calcium; signal transduction; swimming behavior; electrophysiology; proteomics

\section{Introduction}

Ciliates have been studied for their ciliary motility and sensory functions for over 100 years [1]. Among ciliates, Paramecium sp. have served as an excellent model system for the development and function of cilia, in part because of their large numbers of cilia [2]. P. tetraurelia and P. caudatum in particular stand out for their contributions to cilia biology through electrophysiological studies that can 
be combined with behavior, biochemistry, proteomic and genomic studies of wild type and mutant cells. Small changes in ciliary beating, which is determined by the membrane electrical properties, are amplified as easily observable changes in swimming behavior. Therefore, one can monitor the active physiology of the cell and ciliary channels by watching the cells swim, which is easily done with a dissecting scope because of the cells' large size $(>100 \mu \mathrm{m} \times>50 \mu \mathrm{m})$. A depiction of this beautiful cell and its cilia is shown in Figure 1. Kung capitalized upon this connection of physiology and behavior to generate and select mutants that allowed for a genetic dissection of Paramecium behavior [3]. The mutants have led to a more complete understanding of the channels of the ciliary membrane and some surprises about the nature of their control.

In addition to these advantages, the repeating pattern of basal bodies and cilia on the cell surface has made it possible to identify ciliary defects and misalignments that would be very difficult to find in primary ciliary systems, which typically have one cilium per cell. The thousands of cilia present on each Paramecium cell allow for the isolation and collection of these organelles for biochemical studies [4,5]. Such approaches are not as simple using cells containing a single cilium. The cilia of Paramecium are both motile and sensory, containing a " $9+2$ " microtubule organization, with nine outer doublets and a central pair. Most primary non-motile cilia are sensory in function, lacking the central pair of microtubule doublets (reviewed in [6]). Both types of cilia are important for sensory functions, and many of the receptors and channels necessary for chemoresponse are located in the ciliary membrane of Paramecium [7-10]. These attributes of Paramecium have laid the ground work for current molecular and proteomic analyses of its cilia (see [11,12] for new perspective on Paramecium).

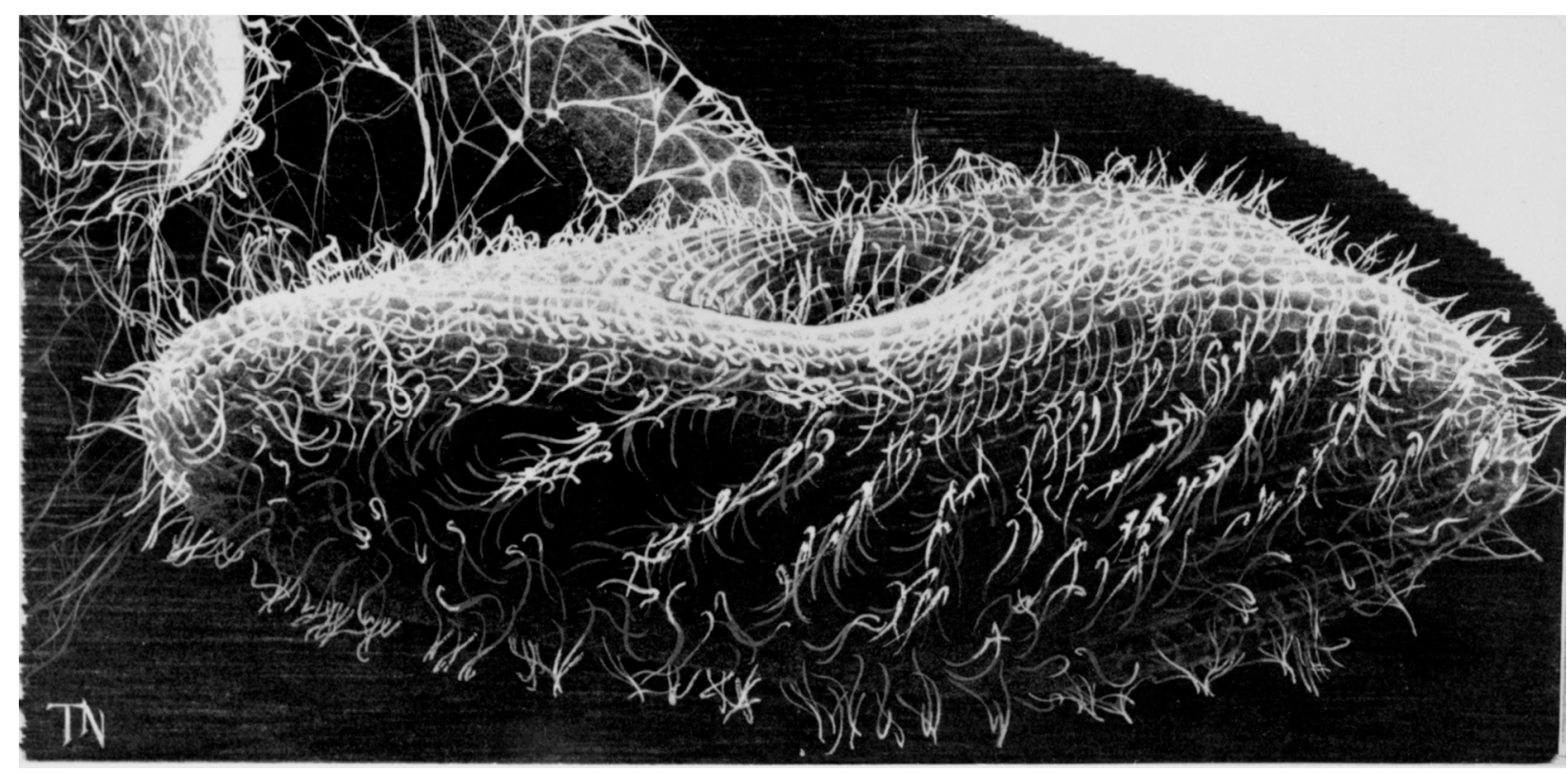

Figure 1. Paramecium tetraurelia showing the waves of cilia beating toward the posterior of the cell. From Grass Calendar, 1985. 


\section{The Advantages of having an Excitable Membrane: Paramecium Broadcasts the Activity of Its Ciliary Ion Channels through Its Behavior}

Paramecium cells beat their thousands of cilia toward the posterior of the cell in waves that propel the cell forward along a helical path. This path changes with the cell's membrane potential. The helix tightens and the cell swims faster with hyperpolarization; with depolarization, the cells slow down and the helix widens. These changes are brought about by changes in the ciliary power stroke and the degree of alignment of the power stroke with the cell's posterior (elegant work of Naitoh, Kaneko, Eckert, and Machemer reviewed in [13-16]). If the depolarization is sufficient, this little swimming neuron [17,18] will activate the voltage gated calcium channels $(\mathrm{Ca}(\mathrm{v}))$, which are exclusively in the cilia [10,19], to create a regenerative depolarization (action potential). The elegant work of Naitoh, Kaneko, Eckert, and Machemer reviewed in [13-16] determined that the $\mathrm{Ca}^{2+}$ entering through $\mathrm{Ca}(\mathrm{v}) \mathrm{s}$ during the action potential interacts with the axoneme to reverse the power stroke of the cilia, sending the cell backward (Figure 2).

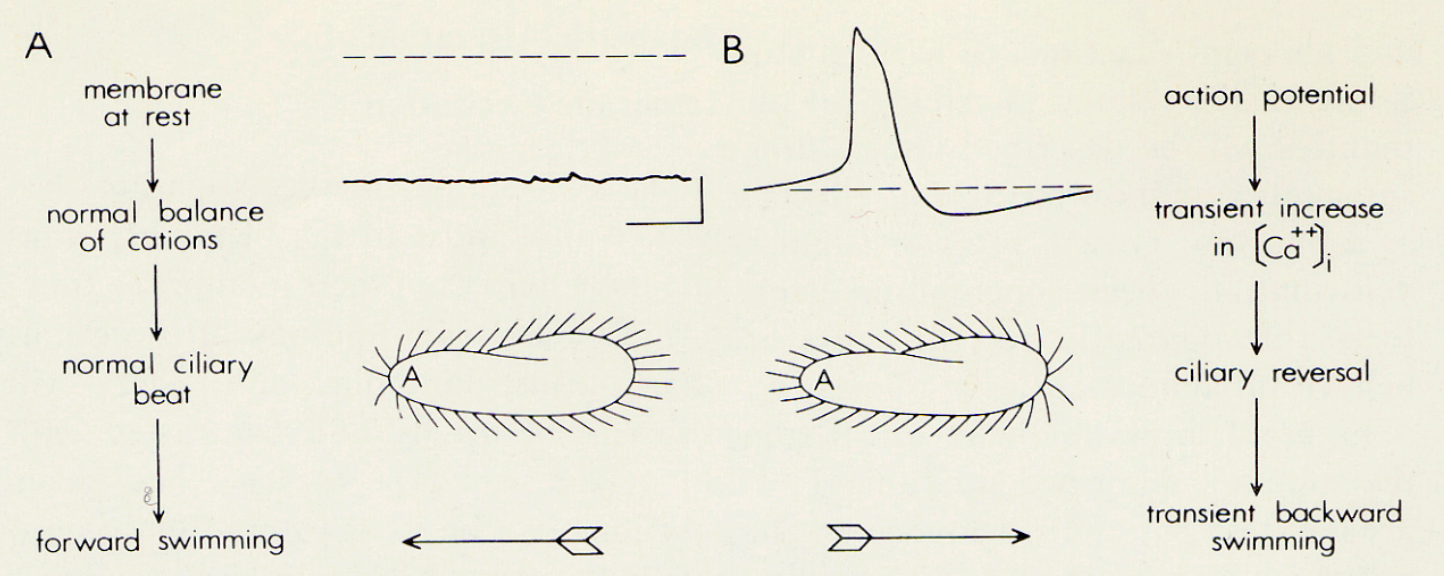

Figure 2. A. These images are to demonstrate that the intracellular membrane potential of Paramecium is negative (about -25 to $-40 \mathrm{mV}$ ); the corresponding ciliary beat is toward the posterior of the cell and the cell swims forward. B. In depolarizing solutions, like high $\mathrm{K}^{+}$or $\mathrm{Ba}^{2+}$, the cell's membrane potential depolarizes and reaches threshold for the action potential. During the action potential calcium enters the cilia through voltage gated channels, the high levels of $\mathrm{Ca}^{2+}$ change the power stroke of the cilia, which now beat most strongly toward the anterior and move the cell backward. The action potential is quickly over and the calcium is removed from or sequestered in the cilia, allowing the ciliary beat and swimming to return to normal. With permission from Science [3].

Because the reversal is temporary, the cell soon swims forward in a new, almost randomly determined direction [20]. The backward swimming ends with a reduction in calcium at the axoneme from $\mu \mathrm{M}$ back to resting $\mathrm{nM}$ concentrations [21]. The $\mathrm{Ca}^{2+}$ from the $\mathrm{Ca}$ (v) conductance is sequestered by proteins like calmodulin and removed from the cilia by calcium pumps [22]. Calcium also feeds back on the channels to inactivate the $\mathrm{Ca}(\mathrm{v}) \mathrm{s}$.

$\mathrm{Ca}^{2+}$ is necessary and sufficient to reverse the power stroke of the cilia, as shown by classic experiments in which cells were made permeable with detergent $[16,23,24]$. These permeabilized cells 
swim forward if provided with $\mathrm{Mg}^{2+}-\mathrm{ATP}$, and reverse their swimming if $\mathrm{Ca}^{2+}$ is also provided at or above $\mu \mathrm{M}$ levels, suggesting that the $\mathrm{Ca}^{2+}$ interacts directly with the axoneme to change the beat. Lieberman and others also demonstrated that these permeabilized cells even retain the metachronal wave as in Figure 1 when induced to swim backward [24].

There are two kinds of $\mathrm{K}$ channels of the cilia that repolarize the cell [15] to bring the membrane potential back to rest after the action potential is initiated. The fast activating $\mathrm{K}_{(\mathrm{v})}$ channel is opened with depolarization, while the slower activating $\mathrm{K}_{(\mathrm{Ca})}$ channel is calcium dependent.

The ability to generate these action potentials sets Paramecium apart from other cells that are not "excitable." The action potential allows the cell to react immediately to situations like bumping into an object or swimming into an area of high salt or repellents [25]. What links these stimuli together is that they all cause depolarizations sufficient to elicit action potentials.

\section{Cilia are Signal Transduction Compartments}

Within the ciliary membrane is the elegant axoneme that is composed of nine outer doublets of microtubules that extend the length of the cilium with two central asymmetrical doublets that are connected to the outer ones by radial spokes (Figure 3). Dynein ATPase arms, which are attached along the length of the outer microtubules, move the B tubules of the doublets on one side of the cilium toward the minus end, forcing the doublets to slide relative to each other and forcing the cilium to bend [26]. When dyneins are active on the opposite side of the cilium, the bend direction changes. The dyneins are classified as Outer and Inner Dynein Arms, for their relative proximity to the cilium surface or interior. The Outer Dynein Arms (ODA) affect power and beat frequency; the Inner Dynein Arms (IDA) generate the ciliary bends and the shape of the ciliary waveform (reviewed in [27]).

The advent of tomography has made it possible to visualize the elegant details of the ciliary structure, specifically the radial spokes in relation to their repeated positions along the outer double microtubules (Figure 4) [28]. The reversal of the power stroke of the cilia causes the reversal of swimming direction; this maneuver requires changes in the interactions among the central pair, the radial spokes and the inner dynein arms. There are signals $\left(\mathrm{Ca}^{2+}\right.$ and cyclic nucleotides) generated in the cilia upon changes in membrane potential that orchestrate the changes in dynein function and ciliary beat frequency and form. The kinases and phosphatases that communicate the signals to the dyneins are part of the axonemal structure [27,29]. The Paramecium model has been useful in sorting out the signaling steps.

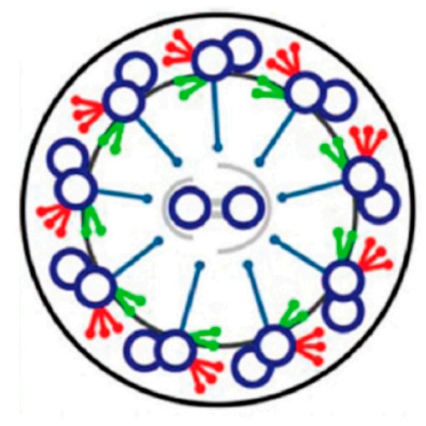

Figure 3. Diagram of a cross section of a cilium. Outer arm dyneins in red; inner arm dyneins in green; doublets of microtubules in blue; radial spokes connecting central pair to outer doublets. Adapted from [30], with permission. 
A

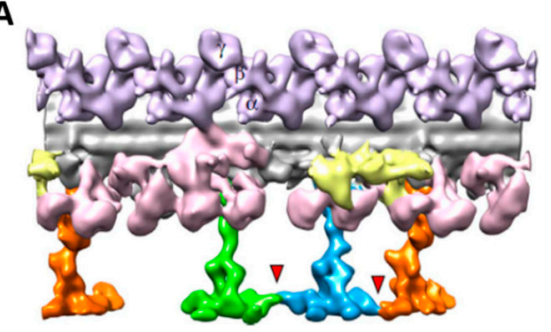

B

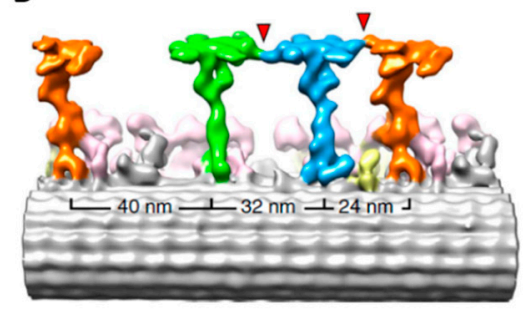

C

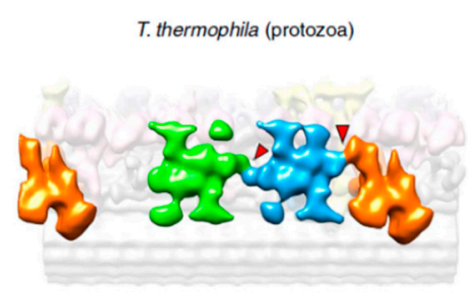

Figure 4. Tomogram from a Tetrahymena cilium. Isosurface renderings show the averaged 96-nm axonemal repeats of the Radial Spoke proteins. Radial spoke proteins 1, 2, and 3 are shown in green, blue, and orange, respectively. The ODA are shaded in purple, IDA are shaded in light pink, and yellow shading indicates the Nexin-Dynein Regulatory Complex. The red arrowheads indicate the connections between the radial spokes. (A) is a longitudinalfront view, (B) longitudinal back view, and (C) a bottom view. Adapted from [28], with permission.

\section{Depolarization and Signal Transduction in the Ciliary Compartment}

Both depolarization and hyperpolarization of Paramecium initiate second messengers and signal transduction pathways that affect the function of axonemal proteins. The initiation of second messengers results in altered ciliary beat form. To effectively and efficiently control the axonemal proteins and ciliary beat, the protein content of the ciliary membrane is different than that of the cell body. A perfect example of this is in the case of Paramecium. In depolarization, the second messenger is intraciliary $\mathrm{Ca}^{2+}$ from the $\mathrm{Ca}$ (v) channels that are located exclusively in the ciliary membrane $[10,19]$. The ciliary $\mathrm{Ca}(\mathrm{V})$ channels are responsible for Paramecium's action potential. Thus, the cilium of Paramecium acts as a $\mathrm{Ca}^{2+}$ signaling compartment with a protein complement that is separate from the cell body membrane.

In neuronal cells, surface membrane protein composition must differ between presynaptic and postsynaptic membranes for neurotransmission. Similarly with cilia, the membrane proteins that determine its sensory and motility functions are mostly distinct from the cell body membrane proteins. Studies utilizing direct recording from mammalian primary cilia [31,32] show that the mammalian primary cilium, as in the case of Paramecium cilia, is a special $\mathrm{Ca}^{2+}$ signaling compartment isolated from the rest of the cell. Thus, the $\mathrm{Ca}^{2+}$-permeable channels, such as the PKD2-dependent channels in mammalian primary cilia [33] and the voltage-gated $\mathrm{Ca}^{2+}$ channels in Paramecium, function within a special $\mathrm{Ca}^{2+}$-signaling organelle [34].

Also within this special $\mathrm{Ca}^{2+}$ compartment are the $\mathrm{K}^{+}$channels that repolarize the membrane potential to resting level and appear to be mostly, if not exclusively, in the cilia [35]. The $\mathrm{Ca}^{2+}$ that activates the $\mathrm{K}_{(\mathrm{Ca})}$ channel has been shown to come from the $\mathrm{Ca}(\mathrm{v})$ channels of the cilia [36]. Husser and workers [37] demonstrated that there is no spillover of $\mathrm{Ca}^{2+}$ from the ciliary action potentials into the cell body, further demonstrating that the $\mathrm{Ca}^{2+}$ that activates $\mathrm{K}_{(\mathrm{Ca})}$ comes from the ciliary $\mathrm{Ca}(\mathrm{v})$.

While other depolarization- or $\mathrm{Ca}^{2+}$-activated channels are not exclusive to the cilia, the proteins present in the ciliary $\mathrm{Ca}^{2+}$ compartment are the ones that participate in controlling ciliary motion following the initiation of action potentials. For example, duration of backward swimming is a function of the activity of cilia-limited $\mathrm{Ca}(\mathrm{v})$ channels, the repolarizing $\mathrm{K}^{+}$conductances, and other $\mathrm{Ca}^{2+}$-dependent 
channels that conduct sodium ions $\left(\mathrm{Na}^{+}\right)$or magnesium ions $\left(\mathrm{Mg}^{2+}\right)$. These channels can prolong the plateau of the action potential and increase the duration of backward swimming. Because there is no spillover of $\mathrm{Ca}^{2+}$ into the cell body to activate plasma membrane channels, the $\mathrm{Ca}^{2+}$ that activates these $\mathrm{Na}(\mathrm{Ca})$ and $\mathrm{Mg}_{(\mathrm{Ca})}$ conductances must derive from the $\mathrm{Ca}$ (v) channels of the cilia. Although these $\mathrm{Na}(\mathrm{Ca})$ and $\mathrm{Mg}_{(\mathrm{Ca})}$ channels might not be exclusively in the cilia, it appears that only those in the cilia affect the duration of backward swimming initiated by the action potential.

The protein that is the likely channel for the $\mathrm{Mg}_{(\mathrm{Ca})}$ in Paramecium is Polycystic Kidney Disease protein 2 (PKD2) which is located in both the cilia and cell membrane [38]. In humans, PKD2 is a critical Transient Receptor Potential Polycystin family (TRPP) channel that, if defective, will lead to autosomal dominant polycystic kidney disease (ADPKD). PKD2 associates in kidney tubule cells with polycystin-1 (PKD1) that is similar to a TRP protein, but does not function as a channel. Flow through the kidney tubules activates the mechanosensory PKD1 and PKD2 complex, allowing $\mathrm{Ca}^{2+}$ to flow into the kidney cells, keeping the cells from proliferating. ADPKD can be traced back to the failure of kidney primary cilia to sense the mechanical stimulus from flow through tubules because the conductance of $\mathrm{Ca}^{2+}$ through ciliary PKD2 protein fails [39,40].

As mentioned, the P. tetraurelia ortholog of PKD2 resides in the cilia and plasma membrane, and, like the mammalian counterpart, requires a very specific protein trafficking route to reach the cilium and a second route to reach the plasma membrane [9]. However, in contrast to mammalian PKD2 that conducts $\mathrm{Ca}^{2+}$, PKD2 in P. tetraurelia appears to conduct $\mathrm{Mg}^{2+}$ because when PKD2 is reduced in P. tetraurelia, the $\mathrm{Mg}^{2+}$-induced prolonged backward swimming behavior and depolarization are concomitantly reduced [38].

A reduction in P. tetraurelia PKD2 produces a phenocopy of the XntA mutant [38], which has lost the $\mathrm{Mg}_{(\mathrm{Ca})}$ conductance that prolongs the action potential in $\mathrm{Mg}^{2+}$ solutions and lost the ability to swim backward in $\mathrm{Mg}^{2+}$ [41,42]. XntA has some structural similarities to PKD1 but does not appear to be the $\mathrm{Mg}^{2+}$ channel [41]. The XntA mutant phenotype can be mostly reversed to wild type with excess PKD2. Immunoprecipitations suggest that PKD2 and XntA interact with each other (directly or indirectly) in both the ciliary and cell membranes. However, the effects of this association are site-specific. When XntA and PKD2 are together in cilia, XntA appears to temper $\mathrm{Mg}^{2+}$-induced behavior and depolarization. Removal of cilia removes this inhibitory effect which can be measured as $\mathrm{Mg}^{2+}$-induced depolarization probably due to the PKD2 and XntA proteins that still interact in the cell membrane. Even deciliated XntA mutant cells show robust depolarizations in $\mathrm{Mg}^{2+}$ as long as PKD2 is available [38].

An additional intraciliary second messenger pathway dependent upon depolarization by the voltage gated $\mathrm{Ca}^{2+}$ channels, described by Schultz and workers, is an increase in intraciliary cyclic GMP [43]. Others established that cyclic GMP (and cyclic AMP, see below) affected the ciliary beat of detergenttreated cells and sheets of cilia that are both accessible to bath solutions [44,45]. Cyclic GMP did not reverse the beat in these preparations, but, depending on the preparation, increased or decreased beat frequency. It is clear, however, that cyclic GMP antagonized the effects of $\mathrm{Ca}^{2+}$ to reverse ciliary beat, leading some to speculate that cyclic GMP helps the recovery of the forward beat [23]. The signal pathway components including guanylyl cyclase, Protein Kinase G (PKG), protein phosphatases and phosphodiesterases are all integral to the cilia, hinting at roles in modifying radial spoke, central pair and dynein functions by post-translational modifications. However, the substrates of the kinase and phosphatases remain undefined. 
As discussed above, the Paramecium made permeable to their extracellular milieu suggest that $\mathrm{Ca}^{2+}$ and not another second messenger acts directly upon the axonemes to reverse the ciliary beat during depolarization. Preston and Saimi [23] argue from analysis of the timing of the reversal compared to signaling pathways, that $\mathrm{Ca}^{2+}$ acts directly upon an axonemal component to reverse the power stroke. The protein interactions that mediate the $\mathrm{Ca}^{2+}$ dependent reversal are not known, but there are candidates among the calmodulin binding proteins of the axoneme that are discussed below.

\section{Hyperpolarization and Signal Transduction in the Ciliary Compartment}

Hyperpolarization in Paramecium is clearly linked to fast forward swimming due to cilia beating more frequently and more toward the posterior [46,47]. As with a neuron, a reduction in extracellular $\mathrm{K}^{+}$in the Paramecium cell's bath solution will hyperpolarize the cell. Likewise, some attractant chemical stimuli cause cells to hyperpolarize $[48,49]$. Both of these methods of hyperpolarizing cells are coupled with fast swimming and a very rapid increase in cyclic AMP [50-53]. Cyclic AMP applied to the ciliated sheets of Paramecium surface modifies the ciliary beat direction and frequency providing a demonstration of the fast swimming upon hyperpolarization [44,54,55]. Similarly, Bonini and Nelson showed increases in beat frequency in permeabilized cells with cyclic AMP [56].

The connection between hyperpolarization and adenylyl cyclase activation to account for the increased cyclic AMP became more clear when Schultz and workers purified an adenylyl cyclase that was activated by a $\mathrm{K}^{+}$conductance $[51,52]$. The subsequent cloning of the genes for adenylyl cyclase helped to explain the regulation of the cyclase by a $\mathrm{K}^{+}$conductance. All sixteen adenylyl cyclase genes in P. tetraurelia appear to code for proteins of this same structure of a cyclase domain linked to a $\mathrm{K}^{+}$ channel domain [52]. This physical linkage between these two functional domains could explain the rapid $\mathrm{K}^{+}$conductance upon stimulation of the cyclase and the association of increases in intracellular cyclic AMP with stimuli that hyperpolarize the cell [51]. It is not clear how the domains of the enzyme communicate, but the association of cyclic AMP and hyperpolarization is clear [56]. The adenylyl cyclase may also be responsible for the coupling of the hyperpolarization with rapid cyclic AMP production when paramecia are stimulated with the attractant glutamate [50], whose receptors are limited to the cilia $[38,57]$.

Adenylyl cyclases are found in both the Paramecium cell body and ciliary membrane. A proteomics analysis enabled determining which ones were specific to the cilia (see below) [58]. Other proteins of the cyclic AMP signaling pathway (such as PKA, phosphatases PP1 and PP2A, A kinase anchor protein (AKAP)) are associated with key proteins of the Chlamydomonas axoneme that affect the wave form and beat of the cilia (reviewed in [27,29]). The signal pathway components are positioned within the axoneme to affect the interactions of the central pair apparatus and radial spokes with the inner dyneins to control ciliary waveform and with the outer dyneins to affect velocity of sliding [27,54]. In Chlamydomonas, a radial spoke functions as an AKAP that positions PKA near the inner dynein arms [27]. Some of the puzzle pieces of the substrates of the signaling kinases are falling into place, such as the $29 \mathrm{kD}$ axonemal protein of the $22 \mathrm{~S}$ dynein outer arm that co-purifies with an inner arm dynein and a substrate of cyclic AMP-dependent phosphorylation in Paramecium [44,55,56]. This $29 \mathrm{kD}$ protein regulates swimming speed and therefore accounts for at least part of the mechanism by which hyperpolarization and increased ciliary cyclic AMP accelerate ciliary beating through increased 
microtubule translocation. While Paramecium axonemal proteins that are substrates of PKA or PKG have been identified $[44,55,59,60]$, their roles in ciliary regulation are not entirely clear. The $\mathrm{Ca}^{2+}$ sensor has yet to be identified in Paramecium.

\section{The Advantage of Mutants}

Preston observed that Paramecium broadcasts the activity of its ion channels through its swimming behavior [61]. This broadcast makes it easy for the observer to intuit the ion channel activity from the cells' swimming speed, turning frequency, and duration of backward swimming during the turn. This connection between behavior and channel activity inspired Kung to carry out a genetic dissection of swimming behavior that led to many useful mutants. The best known of these mutants are the Pawns, named for the chess piece because they cannot move backward for lack of a functional ciliary $\mathrm{Ca}^{2+}$ channel $[3,61,62]$. These mutants, called Pawn in P. tetraurelia and Caudatum Non-Reversal (CNR) in P. caudatum [63] (reviewed in [23]), have been valuable in studies of ion conductances that can be observed in the absence of the ciliary $\mathrm{Ca}$ (v) conductance in these cells [64]. Only $\mathrm{Ca}$ (v) conductance is affected in Pawn; the $\mathrm{K}^{+}$channels of these mutants are normal [65]. Analysis of the P. caudatum CNR mutants made it possible to identify centrin as a player in the regulation of the $\mathrm{Ca}(\mathrm{v})$ channels [66].

Successful function of the $\mathrm{Ca}(\mathrm{v})$ channels in cilia of $P$. tetraurelia is dependent upon the small Pawn proteins. Without these proteins, the cells cannot swim backward or generate an action potential because they lack the $\mathrm{Ca}(\mathrm{v})$ conductance [3], as is the case with deciliated cells [19]. Lodh [67] showed that Pawn mutants have no $\mathrm{Ca}(\mathrm{v})$ channels in their ciliary membrane unless the missing wild type gene was introduced into the cells to rescue the wild type phenotype.

Other mutants shed light on the control of the $\mathrm{K}_{(\mathrm{Ca})}$ channel that is critical for repolarizing the membrane and the $\mathrm{Ca}^{2+}$-activated $\mathrm{Na}^{+}(\mathrm{Na}(\mathrm{Ca}))$ channel that, when open, prolongs the action potential and causes backward swimming [68]. Mutations in two distinct regions of the same gene (for calmodulin) are responsible for drastically different behavioral phenotypes [69]. Without the normal sequence of the $\mathrm{C}$ terminal lobe of calmodulin, the $\mathrm{K}_{(\mathrm{Ca})}$ channel fails to repolarize the cell leading to long backward swimming following an action potential in mutants called Paranoiacs. Without the normal sequence of the $\mathrm{N}$ terminal lobe of calmodulin the $\mathrm{Na}(\mathrm{Ca})$ channel is not activated, causing other mutants called Fast-2 to fail to sustain the long backward swimming in Na solutions [69].

Many other behavioral mutants were isolated and characterized, making it possible to analyze every conductance known in Paramecium with the help of mutants with fascinating names like Paranoiac, Chameleon, Dancer, Restless, and Eccentric [42,61,62,70].

\section{Depletion of Ciliary Proteins}

The sorting of proteins into and out of the cilia is determined by the transition zone between the basal body and cilium [71]. Also critical to developing and maintaining a functional cilium are the processes of trafficking proteins to the surface for incorporation into the axoneme and membrane of the cilium. Paramecium shares the critical proteins for this filtering and trafficking with other systems, but Paramecium stands out as a model to study ciliary channel and signaling proteins. For example, PKD2 depends upon the coat complex of Bardet-Biedl Syndrome (BBS) proteins for proper location in the 
ciliary membrane [72]. Seven BBS proteins along with BBIP10 combine to form a coat complex, important for the trafficking of proteins to the ciliary membrane [73]. Together with Rabin8 and the GTPase Rab8, certain ciliary proteins such as the somatostatin receptor protein 3 (SSTR3) [74] and PKD2 $[9,72]$ require this coat complex to reach the cilia. In Paramecium, both PKD2 and a calcium-activated $\mathrm{K}^{+}$channel (SK1a) are lost from the cilia of cells when the BBS complex proteins are depleted [9]. In contrast, the $P$. tetraurelia ciliary $\mathrm{Ca}_{(\mathrm{v})}$ channels reach the ciliary membrane without these BBS proteins, or upon the accessory subunits such as those that guide mammalian $\mathrm{Ca}$ (v) channels to their membrane locations [75].

A distinct advantage of Paramecium is its repeating pattern of units on its surface from which one or two cilia emanate. This means that basal bodies and their cilia are arranged in neat rows from posterior to anterior. The subsurface rootlets that anchor cilia likewise run in stereotypical rows. When there is a defect in the organization of cilia on the surface, the deviation from the normal pattern broadcasts the problem, much as behavior broadcasts abnormal ciliary physiology. This structural broadcast is not possible in cells with one primary cilium per cell.
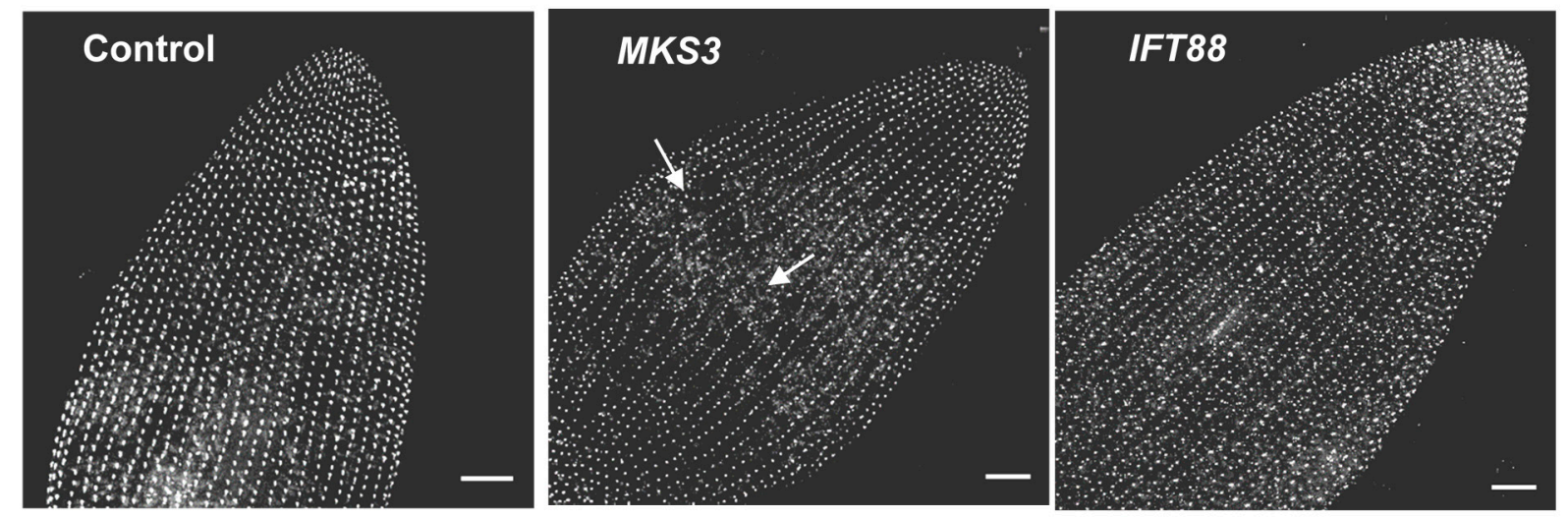

Figure 5. Cells were stained using anti-centrin to visualize the basal bodies. Images represent stacks of $Z$ sections, approximately $10 \mu \mathrm{m}$ thick. The images shown are the dorsal surface of the anterior end of the cell. Basal bodies should be arranged in organized rows, as seen in the control and IFT88 depleted cells. These latter cells are controls for the effects of shortened and lost cilia because they are depleted in a protein that is important for the import of proteins into the cilia. The $M K S 3$ depleted cell (center panel) shows the basal bodies not aligned and no longer in straight rows (white arrows) at the midline of the cell. Scale bars: $10 \mu \mathrm{m}$. With permission from Cilia [9].

The advantage of this highly organized and repetitive surface is highlighted in our study of the conserved transition zone protein meckelin (MKS3). Reduction of MKS3 by RNA interference (RNAi) results in the global shortening and loss of cilia in P. tetraurelia, probably due to problems with the transition zone to pass proteins into the cilia for maintenance [76]. However, there are additional phenotypes of this MKS3 reduction: lines of basal bodies are out of alignment (Figure 5). It appears that the basal bodies and their associated rootlets have wandered off course [76]. This phenotype is very striking, but would be difficult to identify with one cilium per cell. 


\section{Ciliary Membrane Proteomics}

We have attempted to establish that a Paramecium cilium is a special compartment for the membrane and signal transduction proteins that control ciliary beat frequency and wave form. It is estimated from ciliary proteomics and gene expression during cilia regeneration that the Paramecium cilia comprises around 1100 proteins. Not all of these ciliary proteins can be sorted out using mutations or depletion techniques such as RNAi [77]. To make things more complex, the Paramecium genome has undergone three duplications [78], meaning that there are many pairs and triplets of genes. Some of these genes have retained their original function while others have lost function or taken up new functions. Therefore, it is not sufficient to infer the proteome of the Paramecium cilium from the genomics of the cilium even though some genomics tools are quite good [79,80]. Proteomic analysis using high accuracy mass spectrometry is essential to identify proteins that reside in the cilia without the bias of Western blotting techniques.

Two advantages of ciliates like Paramecium for examining the proteins of cilia are that there are thousands of cilia covering each cell and these cilia can be cleanly removed for use in biochemical analysis [81]. (The cell body membranes can also be prepared for biochemistry or for electrical recording [10,19].) The large number of cilia on Paramecium, compared to generally one primary cilium per cell, is advantageous for proteomic analysis of ciliary proteins. It is especially important to have sufficient starting materials to identify channels and other membrane proteins that we have found to be of low-abundance [58].

The Paramecium ciliary proteome is estimated from the genomic analysis ParameciumDB and gene expression during cilia regeneration is estimated to comprise around 1100 proteins [82,83]. Our interest is in the membrane proteins that we know from others' analyses of cilia will differ from the membrane proteome of other (somatic) plasma membrane domains [84]. The transmembrane proteins should include receptors and ion channel involved in receiving chemical and mechanical stimuli from the environment and in modifying the signal within the cilium to change swimming behavior in response to stimuli. Also important to identify are the signal transduction components (kinases, phosphatases, phosphodiesterases, cyclases) that allow for depolarization and hyperpolarization to modify axoneme function and ciliary beat.

In order to concentrate the membrane proteins of the cilia, we isolated cilia and further separated them into ciliary membrane and axonemes [58] as previously described [5]. We further treated the ciliary membrane with Triton-X114 for phase separation in order to concentrate transmembrane and lipidated proteins into the detergent phase $[58,85]$. This detergent treatment also had the beneficial effect of cleaving the Glycosylphosphatidyl inositol (GPI)-anchor of the peripheral proteins that are inserted into the outer leaflet of the membrane by this anchor [86,87]. The cleaved GPI-anchored proteins partitioned into the aqueous phase, allowing us to analyze the detergent soluble proteins in their absence. Since two thirds by mass of the surface proteins are GPI-anchored proteins [88], separating them into the aqueous phase allowed us to concentrate the low abundance trans-membrane proteins in the detergent phase for mass spectrometry.

Our mass spectrometric analyses of cilia, ciliary membrane and ciliary membrane detergent phase show that membrane proteins makeup about $10 \%$ of the total proteins. Of proteins identified from the detergent phase of Triton X-114 phase separation, 55\% are the membrane proteins, which contain proteins with predicted transmembrane domains or proteins associating with the membrane through lipid 
moiety (ion channels, ion pumps, adenylyl cyclase, $\mathrm{Ca}^{2+}$ dependent protein kinases and phosphatase, and Rab GTPases).

Figure 6 demonstrates that the trans-membrane proteins of interest to us for their function in ciliary motility and sensory response are enriched in the detergent phase of Triton X-114 phase separation. Note that the signal components that we have discussed in this review are prevalent among the proteins in the detergent phase (blue in Figure 6) and that structural proteins are prevalent in the whole cilia (green Figure 6). Mass spectrometry allowed us to identify the three voltage gated calcium channels from among at least 40 known in the genome that are expressed in the cilia. Our study allowed us to determine that a particular small conductance $\mathrm{Ca}^{2+}$-activated $\mathrm{K}^{+}$channel (SK1a) and a $\mathrm{Mg}^{2+}$-channel like exchanger (XntA) really are in the cilia. Likewise, we were able to determine which adenylyl cyclase is localized in the cilia for control by hyperpolarization. The presence of these proteins in cilia has been validated using RNAi, tagged protein expression, and immunoprecipitation $[9,52,58]$.

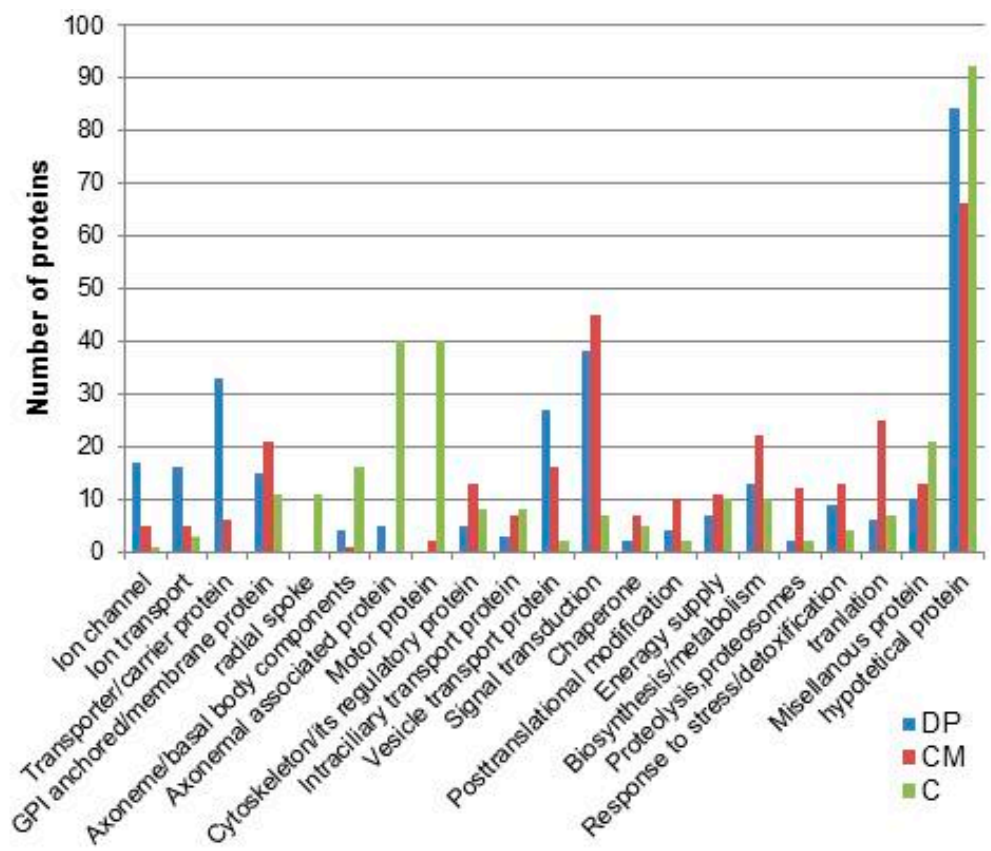

Figure 6. Frequency of proteins organized by function from the 300 most abundant proteins from each preparation: non-fractionated cilia (C), ciliary membrane $(\mathrm{CM})$, and the detergent phase of Triton X-114 phase separation (DP). With permission from Elsevier [58].

One of our interests is in the mechanism of removal of $\mathrm{Ca}^{2+}$ that enters through the $\mathrm{Ca}$ (v) channels. It is thought to bind to calmodulin and be removed by plasma membrane calcium ATPase pumps (PMCA) [22]. Our proteomic analysis of the transmembrane proteins shows that several PMCAs are in the ciliary membrane, but, judging from peptide numbers, PMCA18 and 19 are the most enriched [58]. (Indeed, our undergraduate course entitled "Biology 205: Advanced Genetics" that analyzes Paramecium ciliary membrane by mass spectrometry consistently finds these PMCAs, although the $\mathrm{Ca}(\mathrm{v})$ is extremely difficult to find.) To validate this finding, we performed RNA interference (RNAi) for PMCA18 and 19 and found prolonged backward swimming, which indicates that ciliary $\mathrm{Ca}^{2+}$ remains high without the activity of these pumps [89]. We also used epitope tagged VGCC1c in ciliary membrane to show that this $\mathrm{Ca}(\mathrm{v})$ channel immunoprecipitates with PMCA18 and 19 (confirmed by mass spectrometry [89]). 
The co-localization of the $\mathrm{Ca}(\mathrm{v})$ and PMCA in the cilium is intriguing to us. The ciliary channel conducts very few $\mathrm{Ca}^{2+}$ molecules in order to achieve a $\mu \mathrm{M}$ concentration and reverse ciliary beat [21]. Close proximity of the $\mathrm{Ca}(\mathrm{v})$ and PMCA in cilia could provide that tight regulation of the $\mathrm{Ca}^{2+}$ entering the cilium. Since Paramecium cilia are separate lipid membrane compartments as well as protein and $\mathrm{Ca}^{2+}$ compartments [90], it is possible that association of the PMCAs and channels could be facilitated by lipid rafts. Indeed, the phase separation that we use to enrich for membrane proteins also enriches for proteins that reside in lipid rafts and PMCAs in other systems are known to be in lipid rafts [91,92]. The trypanosome flagellum is enriched in lipid rafts, and lipid rafts appear to play a role in localizing proteins, including a calcium sensor, to their flagella [93].

The next level of proteomic analysis of Paramecium cilia will be analysis of post-translational modifications of the signaling pathways that implement the depolarization and hyperpolarization signaling to change the ciliary beat.

\section{Summary}

Paramecium species, especially $P$. tetraurelia and caudatum, provide a broad and deep foundation for research. The confluence of genetics, behavior, and electrophysiology brought us a new understanding of ciliary motility. Structural studies, biochemistry, genomics, and molecular biological studies followed with important insights into the key protein and second messenger players in the control of ciliary beating. All of these insights have come together as we use mass spectrometry in an unbiased way to identify and confirm the proteins involved in ciliary beat control.

\section{Acknowledgments}

We would like to acknowledge the Vermont Genetics Network (VGN) Proteomics Facility and Ying Wai Lam for his assistance with the proteomics work, supported by an IDeA from NIGMS of NIH, P20 GM103449. We would also like to acknowledge Todd Clason at the University of Vermont whose imaging facilities are supported by NIH grant number 5 P30 RR032135 from COBRE Program of the National Center for Research Resources and 8 P30 GM103498 from NIGMS. Lastly, we would like to thank Mark Winey for the Tetrahymena Anti-centrin antibody used to highlight the basal bodies in Figure 5.

\section{Author Contributions}

J.Y. contributed to the preparation and writing of the manuscript, final edits and submission; M.S.V. contributed to the writing and editing of the manuscript and final edits; J.V.H. contributed to the preparation, oversight, writing, and editing of the manuscript.

\section{Conflicts of Interest}

The authors declare no conflict of interest. 


\section{References}

1. Jennings, H.S. Behavior of the Lower Organisms. The Columbia University Press, The MacMillan Company: New York, NY, USA, 1906.

2. Kleene, S.; Van Houten, J.L. Electrical signaling in motile and primary cilia. BioScience 2014, 64, 1092-1102.

3. Kung, C.; Chang, S.Y.; Satow, Y.; Houten, J.V.; Hansma, H. Genetic dissection of behavior in Paramecium. Science 1975, 188, 898-904.

4. Wright, M.V.; Van Houten, J.L. Characterization of a putative $\mathrm{Ca}^{2+}$-transporting $\mathrm{Ca}^{2+}$-ATPase in the pellicles of Paramecium tetraurelia. Biochim. Biophys. Acta 1990, 1029, 241-251.

5. Adoutte, A.; Ramanathan, R.; Lewis, R.M.; Dute, R.R.; Ling, K.Y.; Kung, C.; Nelson, D.L. Biochemical studies of the excitable membrane of Paramecium tetraurelia. III. Proteins of cilia and ciliary membranes. J. Cell Biol. 1980, 84, 717-738.

6. Fliegauf, M.; Benzing, T.; Omran, H. Mechanisms of disease - when cilia go bad: Cilia defects and ciliopathies. Nat. Rev. Mol. Cell. Biol. 2007, 8, 880-893.

7. Weeraratne, S.D. GPI receptors in folate chemosensory transduction in Paramecium tetraurelia. Ph.D. Thesis, University of Vermont, Burlington, VT, USA, 2007.

8. Jacobs, C.L. NMDA receptor associated protein in Paramecium and it involvement in glutamate chemoresponse. MS thesis, University of Vermont, Burlington, VT, USA, 2007.

9. Valentine, M.S.; Rajendran, A.; Yano, J.; Weeraratne, S.D.; Beisson, J.; Cohen, J.; Koll, F.; Van Houten, J. Paramecium BBS genes are key to presence of channels in cilia. Cilia 2012, 1, doi:10.1186/2046-2530-1-16.

10. Machemer, H.; Ogura, A. Ionic conductances of membranes in ciliated and deciliated Paramecium. J. Physiol. 1979, 296, 49-60.

11. Fleischman, J. Old lab animal model systems gain new respect - Paramecium redux. ASCB Post 2014, Available Online: http://www.ascb.org/old-lab-animal-model-systems-gain-new-respectparamecium-redux/ (accessed on 2 July 2015).

12. Beisson, J.; Bétermier, M.; Bré, M.-H.; Cohen, J.; Duharcourt, S.; Duret, L.; Kung, C.; Malinsky, S.; Meyer, E.; Preer, J.R.; et al. Paramecium tetraurelia: The renaissance of an early unicellular model. Cold Spring Harb. Protoc. 2010, 2010, doi:10.1101/pdb.emo140.

13. Machemer, H. Electrophysiology. In Paramecium, Gortz, H.-D., Ed.; Springer-Verlag: Berlin, Germany, 1988; pp. 186-215.

14. Machemer, H. Motor control of cilia. In Paramecium, Gortz, H.-D., Ed.; Springer-Verlag: Berlin, Germany, 1988; pp. 216-235.

15. Brehm, P.; Eckert, R. An electrophysiological study of the regulation of ciliary beating frequency in Paramecium. J. Physiol. 1978, 283, 557-568.

16. Naitoh, Y.; Kaneko, H. Reactivated triton-extraced models of Paramecium: Modifications of ciliary movement by calcium ions. Science 1972, 176, 523-524.

17. Preston, R.R.; Kink, J.A.; Hinrichsen, R.D.; Saimi, Y.; Kung, C. Calmodulin mutants and $\mathrm{Ca}^{2+}$-dependent channels in Paramecium. Annu. Rev. Physiol. 1991, 53, 309-319.

18. Kung, C.; Saimi, Y. $\mathrm{Ca}^{2+}$ channels of Paramecium: A multidisciplinary study. In Current Topics in Membranes and Transport; Academic Press: San Diego, CA, USA 1985; Volume 23, pp. 45-66. 
19. Dunlap, K. Localization of calcium channels in Paramecium caudatum. J. Physiol. 1977, 271, 119-133.

20. Van Houten, J.; Van Houten, J. Computer analysis of Paramecium chemokinesis behavior. J. Theor. Biol. 1982, 98, 4453-4468.

21. Eckert, R. Bioelectric control of ciliary activity. Science 1972, 176, 473-481.

22. Plattner, H. Calcium signalling in the ciliated protozoan model, Paramecium: Strict signal localisation by epigenetically controlled positioning of different $\mathrm{Ca}^{2+}$-channels. Cell Calcium $\mathbf{2 0 1 5}$, 57, 203-213.

23. Preston, R.; Saimi, Y. Calcium ions and the regulation of motility in Paramecium. In Ciliary and Flagellar Membranes; Bloodgood, R.A., Ed.; Plenum Publishing Corp.: New York, NY, USA, 1990; pp 173-200.

24. Lieberman, S.J.; Hamasaki, T.; Satir, P. Ultrastructure and motion analysis of permeabilized Paramecium capable of motility and regulation of motility. Cell. Motil. Cytoskel. 1988, 9, 73-84.

25. Van Houten, J. Chemosensory transduction in Paramecium. Eur. J. Protistol. 1998, 34, 301-307.

26. Satir, P.; Heuser, T.; Sale, W. A structural basis for how motile cilia beat. BioScience 2014, 64, 1073-1083.

27. Porter, M.; Sale, W. The 9+2 axoneme anchors multiple inner arm dyneins and a network of kinases and phosphatases that control motility. J. Cell Biol. 2000, 151, F37-F42.

28. Lin, J.; Yin, W.; Smith, M.C.; Song, K.; Leigh, M.W.; Zariwala, M.A.; Knowles, M.R.; Ostrowski, L.E.; Nicastro, D. Cryo-electron tomography reveals ciliary defects underlying human RSPH1 primary ciliary dyskinesia. Nat. Commun. 2014, 5, 5727, doi: 10.1038/ncomms6727.

29. Wirschell, M.; Yamamoto, R.; Alford, L.M.; Gokhale, A.; Gaillard, A.R.; Sale, W. Regulation of ciliary motility: Conserved protein kinases and phosphatases are targeted and anchored in the ciliary axoneme. Arch. Biochem. Biophys. 2011, 510, 93-100.

30. Pedersen, L.; Schroder, J.; Satir, P.; Christensen, S. The ciliary cytoskeleton. Compr. Physiol. 2012, 2, 779-803.

31. DeCaen, P.G.; Delling, M.; Vien, T.N.; Clapham, D.E. Direct recording and molecular identification of the calcium channel of primary cilia. Nature 2013, 504, 315-318.

32. Delling, M.; DeCaen, P.G.; Doerner, J.F.; Febvay, S.; Clapham, D.E. Primary cilia are specialized calcium signalling organelles. Nature 2013, 504, 311-314.

33. Delmas, P.; Padilla, F.; Osorio, N.; Coste, A.; Baasner, A.; Raoux, M.; Crest, M. Polycystins, calcium signaling and human diseases. Biochem. Biophys. Res. Commun. 2004, 322, 1374-1383.

34. Jin, X.; Mohieldin, A.M.; Muntean, B.S.; Green, J.A.; Shah, J.V.; Mykytyn, K.; Nauli, S.M. Cilioplasm is a cellular compartment for calcium signaling in response to mechanical and chemical stimuli. Cell. Mol. Life Sci. 2014, 71, 2165-2178.

35. Brehm, P.; Dunlap, K.; Eckert, R. Calcium-dependent repolarization in Paramecium. J. Physiol. 1978, 274, 639-654.

36. Satow, Y.; Kung, C. Ca-induced $\mathrm{K}^{+}$-outward current in Paramecium tetraurelia. J. Exp. Biol. 1980, 88, 293-303.

37. Husser, M.; Hardt, M.; Blanchard, M.-P.; Hentschel, J.; Klauke, N.; Plattner, H. One-way calcium spill-over during signal transduction in Paramecium cells: From cortex into cilia but not the reverse. Cell Calcium 2004, 36, 349-358. 
38. Valentine, M. (University of Vermont: Burlington, VT, USA). Personal communication, 2015.

39. Gerdes, J.M.; Davis, E.E.; Katsanis, N. The vertebrate primary cilium in development, homeostasis, and disease. Cell 2009, 137, 32-45.

40. Berbari, N.; O'Connor, A.; Haycraft, C.; Yoder, B. The primary cilium is a complex signaling center. Curr. Biol. 2009, 19, R526-R535.

41. Haynes, W.J.; Kung, C.; Saimi, Y.; Preston, R.R. An exchanger-like protein underlies the large $\mathrm{Mg}^{2+}$ current in Paramecium. Proc. Natl. Acad. Sci. USA 2002, 99, 15717-15722.

42. Preston, R.R.; Kung, C. Isolation and characterization of Paramecium mutants defective in their response to magnesium. Genetics 1994, 137, 759-769.

43. Schultz, J.; Polh, T.; Klumpp, S. Voltage-gated $\mathrm{Ca}^{2+}$ entry into Paramecium linked to intraciliary increase in cyclic GMP. Nature 1986, 322, 271-273.

44. Noguchi, M.; Kurahashi, S.; Kamachi, H.; Inoue, H. Control of the ciliary beat by cyclic nucleotides in intact cortical sheets from Paramecium. Zool. Sci. 2004, 21, 1167-1175.

45. Bonini, N.; Nelson, D. Differential regulation of Paramecium ciliary motility by cAMP and cGMP. J. Cell Biol. 1988, 106, 1615-1623.

46. Machemer, H. Frequency and directional responses of cilia to membrane potential changes in Paramecium. J. Comp. Physiol. 1974, 92, 293-316.

47. Machemer, H. Cellular behavior modulated by ions: Electrophysiological implications. J. Protozool. 1989, 36, 463-487.

48. Van Houten, J.L. Membrane potential changes during chemokinesis in Paramecium. Science 1979, 204, 1100-1103.

49. Preston, R.; Van Houten, J. Chemoreception in Paramecium: Acetate - and folate-induced membrane hyperpolarization. J. Comp. Physiol. 1987, 160, 525-536.

50. Yang, W.; Braun, C.; Plattner, H.; Purvee, J.; Van Houten, J.L. Cyclic nucletotides in gluamate chemosensory signal transduction of Paramecium. J. Cell Sci. 1997, 110, 1567-1572.

51. Schultz, J.E.; Klumpp, S.; Benz, R.; Schurhoff-Goeters, W.J.; Schmid, A. Regulation of adenylyl cyclase from Paramecium by an intrinsic potassium conductance. Science 1992, 255, 600-603.

52. Weber, J.H.; Vishnyakov, A.; Hambach, K.; Schultz, A.; Schultz, J.E.; Linder, J.U. Adenylyl cyclases from Plasmodium, Paramecium and Tetrahymena are novel ion channel/enzyme fusion proteins. Cell. Signal. 2004, 16, 115-125.

53. Klumpp, S.; Gierlich, D.; Schultz, J.E. Adenylate cyclase and guanylate cyclase in the excitable ciliary membrane from Paramecium: Separation and regulation. FEBS Lett. 1984, 171, 95-99.

54. Kutomi, O.; Hori, M.; Ishida, M.; Tominaga, T.; Kamachi, H.; Koll, F.; Cohen, J.; Yamada, N.; Noguchi, M. Outer dynein arm light chain 1 is essential for controlling the ciliary response to cyclic AMP in Paramecium tetraurelia. Eukaryot. Cell 2012, 11, 645-653.

55. Hamasaki, T.; Barkalow, K.; Richmond, J.; Satir, P. cAMP-stimulated phosphorylation of an axonemal polypeptide that copurifies with the $22 \mathrm{~S}$ dynein arm regulates microtubule translocation velocity and swimming speed in Paramecium. Proc. Natl. Acad. Sci. USA 1991, 88, 7918-7922.

56. Bonini, N.M.; Gustin, M.C.; Nelson, D.L. Regulation of ciliary motility by membrane potential in Paramecium: A role for cyclic AMP. Cell. Motil. Cytoskel. 1986, 6, 256-272.

57. Preston, R.R.; Saimi, Y.; Kung, C. Evidence for two $\mathrm{K}^{+}$currents activated upon hyperpolarization of Paramecium tetraurelia. J. Membr. Biol. 1990, 115, 41-50. 
58. Yano, J.; Rajendran, A.; Valentine, M.S.; Saha, M.; Ballif, B.A.; Van Houten, J.L. Proteomic analysis of the cilia membrane of Paramecium tetraurelia. J. Proteomics 2013, 78, 113-122.

59. Noguchi, M.; Sasaki, J.Y.; Kamachi, H.; Inoue, H. Protein phosphatase 2C is involved in the cAMPdependent ciliary control in Paramecium caudatum. Cell. Motil. Cytoskel. 2003, 54, 95-104.

60. Bonini, N.; Nelson, D. Phosphoproteins associated with cyclic nucleotide stimulation of ciliary motility in Paramecium. J. Cell Sci. 1990, 95, 219-230.

61. Preston, R. Genetic dissection of $\mathrm{Ca}^{2+}$-dependent ion channel function in Paramecium. BioEssays 1990, 12, 273-281.

62. Saimi, Y.; Kung, C. Behavioral genetics of Paramecium. Annu. Rev. Genet. 1987, 21, 47-65.

63. Takahashi, M. Behavioral mutants in Paramecium caudatum. Genetics 1979, 91, 393-408.

64. Oertel, D.; Schein, S.; Kung, C. Separation of membrane currents using a Paramecium mutant. Nat. Neurosci. 1977, 268, 120-124.

65. Satow, Y.; Kung, C. Membrane currents of pawn mutants of the pwA group in Paramecium tetraurelia. J. Exp. Biol. 1980, 84, 57-71.

66. Gonda, K.; Yoshida, A.; Oami, K.; Takahashi, M. Centrin is essential for the activity of the ciliary reversal-coupled voltage-gated $\mathrm{Ca}^{2+}$ channels. Biochem. Biophys. Res. Commun. 2004, 323, 891-897.

67. Lodh, S. Characterization of pwA and pwB Proteins in Paramecium. Ph.D. Thesis, University of Vermont, Burlington, VT, USA, 2012.

68. Kung, C.; Preston, R.R.; Maley, M.E.; Ling, K.Y.; Kanabrocki, J.A.; Seavey, B.R.; Saimi, Y. In vivo Paramecium mutants show that calmodulin orchestrates membrane responses to stimuli. Cell Calcium 1992, 13, 413-425.

69. Kink, J.A.; Maley, M.E.; Preston, R.R.; Ling, K.Y.; Wallen-Friedman, M.A.; Saimi, Y.; Kung, C. Mutations in Paramecium calmodulin indicate functional differences between the C-terminal and N-terminal lobes in vivo. Cell 1990, 62, 165-174.

70. Preston, R.R.; Saimi, Y.; Martinac, B.; Kung, C. Genetic analysis of ion channels of prokaryotes and lower eukaryotes. Curr. Opin. Genet. Dev. 1992, 2, 780-784.

71. Reiter, J.F.; Blacque, O.E.; Leroux, M.R. The base of the cilium: Roles for transition fibers and the transition zone in ciliary formation, maintenance and compartmentalization. EMBO Rep. 2012, 13, 608-618.

72. Hoffmeister, H.; Babinger, K.; Gurster, S.; Cedzich, A.; Meese, C.; Schadendorf, K.; Osten, L.; de Vries, U.; Rascle, A.; Witzgall, R. Polycystin-2 takes different routes to the somatic and ciliary plasma membrane. J. Cell Biol. 2011, 192, 631-645.

73. Jin, H.; White, S.R.; Shida, T.; Schulz, S.; Aguiar, M.; Gygi, S.P.; Bazan, J.F.; Nachury, M.V. The conserved Bardet-Biedl Syndrome proteins assemble a coat that traffics membrane proteins to cilia. Cell 2010, 141, 1208-1219.

74. Klinger, M.; Wang, W.; Kuhns, S.; Barenz, F.; Drager-Meurer, S.; Pereira, G.; Gruss, O.J. The novel centriolar satellite protein SSX2IP targets CEP290 to the ciliary transition zone. Mol. Biol. Cell 2014, 25, 495-507.

75. Dolphin, A.C. Calcium channel auxiliary $\alpha 2 \delta$ and $\beta$ subunits: Trafficking and one step beyond. Nat. Rev. Neurosci. 2012, 13, 542-555. 
76. Picariello, T.; Valentine, M.S.; Yano, J.; Van Houten, J. Reduction of meckelin leads to general loss of cilia, ciliary microtubule misalignment and distorted cell surface organization. Cilia 2014, 3, doi:10.1186/2046-2530-3-2.

77. Galvani, A.; Sperling, L. RNA interference by feeding in Paramecium. Trends Genet. 2002, 18, 11-12.

78. Aury, J.-M.; Jaillon, O.; Duret, L.; Noel, B.; Jubin, C.; Porcel, B.; Segurens, B.; Daubin, V.; Anthouard, V.; Aiach, N.; et al. Global trends of whole-genome duplications revealed by the ciliate Paramecium tetraurelia. Nature 2006, 444, 171-178.

79. Arnaiz, O.; Malinowska, A.; Klotz, C.; Sperling, L.; Dadlez, M.; Koll, F.; Cohen, J. Cildb: A knowledgebase for centrosomes and cilia. Database 2009, 2009, bap022, doi:10.1093/database/bap022.

80. Arnaiz, O.; Cohen, J.; Tassin, A.-M.; Koll, F. Remodeling Cildb, a popular database for cilia and links for ciliopathies. Cilia 2014, 3, 1-10.

81. Nelson, D. Preparation of cilia and subciliary fractions from Paramecium. In Methods in Cell Biology; Academic Press, Inc.: San Diego, CA, USA, 1995; Volume 47, pp. 17-24.

82. Arnaiz, O.; Cain, S.; Cohen, J.; Sperling, L. ParameciumDB: A community resource that integrates the Paramecium tetraurelia genome sequence with genetic data. Nucleic Acids Res. 2007, 35, D439-D444.

83. Arnaiz, O.; Sperling, L. ParameciumDB in 2011: New tools and new data for functional and comparative genomics of the model ciliate Paramecium tetraurelia. Nucleic Acids Res. 2011, 39, D632-D636.

84. Bloodgood, R.A. The future of ciliary and flagellar membrane research. Mol. Biol. Cell. 2012, 23, 2407-2411.

85. Mathias, R.A.; Chen, Y.-S.; Kapp, E.A.; Greening, D.W.; Mathivanan, S.; Simpson, R.J. Triton X114 phase separation in the isolation and purification of mouse liver microsomal membrane proteins. Methods 2011, 54, 396-406.

86. Paquette, C.A.; Rakochy, V.; Bush, A.; van Houten, J.L. Glycophosphatidylinositol-anchored proteins in Paramecium tetraurelia: Possible role in chemoresponse. J. Exp. Biol. 2001, 204, 2899-2910.

87. Yano, J.; Rachochy, V.; van Houten, J.L. Glycosyl phosphatidylinositol-anchored proteins in chemosensory signaling: Antisense manipulation of Paramecium tetraurelia PIG-A gene expression. Eukaryot. Cell 2003, 2, 1211-1219.

88. Capdeville, Y.; Benwakrim, A. The major ciliary membrane proteins in Paramecium primaurelia are all glycosylphosphatidylinositol-anchored proteins. Eur. J. Cell Biol. 1996, 70, 339-346.

89. Yano, J. (University of Vermont: Burlington, VT, USA). Personal communication, 2015.

90. Rhoads, D.E.; Kaneshiro, E.S. Characterizations of phospholipids from Paramecium tetraurelia cells and cilia. J. Protozool. 1979, 26, 329-338.

91. Sepúlveda, M.R.; Hidalgo-Sánchez, M.; Mata, A.M. Localization of endoplasmic reticulum and plasma membrane $\mathrm{Ca}^{2+}$-ATPases in subcellular fractions and sections of pig cerebellum. Eur. J. Neurosci. 2004, 19, 542-551. 
92. Pani, B.; Singh, B.B. Lipid rafts/caveolae as microdomains of calcium signaling. Cell. Calcium 2009, 45, 625-633.

93. Tyler, K.M.; Fridberg, A.; Toriello, K.M.; Olson, C.L.; Cieslak, J.A.; Hazlett, T.L.; Engman, D.M. Flagellar membrane localization via association with lipid rafts. J. Cell Sci. 2009, 122, 859-866.

(C) 2015 by the authors; licensee MDPI, Basel, Switzerland. This article is an open access article distributed under the terms and conditions of the Creative Commons Attribution license (http://creativecommons.org/licenses/by/4.0/). 